pag

Business School

WORKING PAPER SERIES

Working Paper

2014-590
Dependence and extreme dependence of crude oil and natural gas prices with applications to risk management

Riadh Aloui

Mohamed Safouane Ben Aïssa

Shawkat Hammoudeh

Duc Khuong Nguyen

http://www.ipag.fr/fr/accueil/la-recherche/publications-WP.html

IPAG Business School

184, Boulevard Saint-Germain

75006 Paris

France 


\title{
Dependence and extreme dependence of crude oil and natural gas prices with applications to risk management
}

\author{
Riadh Aloui ${ }^{\mathrm{a}}$, Mohamed Safouane Ben Aïssa ${ }^{\mathrm{a}}$, Shawkat Hammoudeh ${ }^{*, \mathrm{~b}}$, \\ Duc Khuong Nguyen ${ }^{\mathrm{c}}$ \\ ${ }^{a}$ LAREQUAD \& FSEGT, University of Tunis El Manar, B.P 248 El Manar II 2092 \\ Tunis, Tunisia \\ ${ }^{b}$ College of Business, Drexel University Philadelphia, PA 19104, USA \\ ${ }^{c}$ IPAG Lab, IPAG Business School, 184 Boulevard Saint-Germain, 75006 Paris, France
}

\begin{abstract}
In this article, we show how the copula-GARCH approach can be appropriately used to investigate the conditional dependence structure between the crude oil and natural gas markets as well as to derive implications for portfolio risk management in extreme economic conditions. Using daily price data from January 1997 to October 2011, our in-sample results show evidence of asymmetric dependence between the two markets. The crude oil and gas markets tend to co-move closely together during bullish periods, but not at all during bearish periods. Moreover, taking the extreme comovement into account leads to an improvement in the accuracy of the out-of-sample Value-at-Risk forecasts.
\end{abstract}

JEL classification: C51, C58, Q41, Q47.

Keywords: Copulas, extreme dependence measures, crude oil, natural gas, VaR.

*Corresponding author. Phone: 215-895-6673 - Fax: 215-895-6975.

Email addresses: riadh.aloui@isg.rnu.tn (Riadh Aloui), safouane.benaissa@univmed.fr (Mohamed Safouane Ben Aïssa), hammousm@drexel.edu (Shawkat Hammoudeh), duc.nguyen@ipag.fr (Duc Khuong Nguyen) 


\section{Introduction}

Crude oil and natural gas are among the most important fuels in the modern economy because of their extensive use by many economic sectors. They are substitutes in consumption and also complements, as well as rivals, in production of electricity. These characteristics explain why prices of these commodities tend or are expected to comove closely over time. Understanding the dependence patterns between the prices of oil and gas, particularly in extreme conditions and given their fat tail behavior, is thus of paramount importance not only for energy-policy decision-making regarding consumption, production and investment, but also for portfolio risk management and hedging issues. Indeed, energy prices of those two fuels influence the incentives to invest in different types of energy-using equipment. Energy traders may find the tendency of the prices to adjust to a certain relative relationship or parity as the basis for a trading strategy.

Historically, there was a 10-1 price relationship between one barrel of oil and one million BTUs of natural gas in the 1990s but more recently this relative price relationship declined to a 6 - 1 ratio which is close to their thermal parity (Brown and Yucel, 2008; Hartley et al., 2008). None of these rules perform well over our sample. There have been periods, occurring more frequently, in which natural gas prices seemed to have decoupled from oil prices. During periods such as 2001, 2003, and 2005, natural gas prices rose above their historical relationship with oil prices. The facilities that are able to switch between natural gas and residual fuel oil declined (Brown and Yucel, 
2008). More recently, especially after the discovery of hydraulic fracturing, natural gas prices dropped below this historical relationship. Moreover, these prices have recently exhibited high volatility, extreme movements and sharp spikes in responding to changes in geopolitical risk, economic factors, extraction and efficiency techniques, and occurrences of natural events. These factors and events have pushed those prices into the tails of the distributions during those periods.

Previous research concentrates on the investigation of the linear relationship between the two prices. Given the size of the global oil market relative to the regional natural gas markets, most of these studies find a stable long-run directional relationship between the two prices and a directional influence from the oil prices to the natural gas prices in the United States and the United Kingdom (Yucel and Guo, 1994; Asche et al., 2006). Recently, the movements of both prices have headed toward the opposite tails of their distributions, thus warranting a new examination.

The objectives of this study are: $i$ ) to examine the extreme comovements between the global benchmark prices of the WTI crude oil and Henry Hub natural gas in the tails of return distributions; ii) to discern the strength of relative dependence between these prices during bullish and bearish times such as the periods that predate and post-date the most recent financial crisis; and $i i i$ ) to show the implications of these potentially asymmetric interactions on market risk forecasting for an oil and gas portfolio.

Compared to the existing literature, we make several significant contri- 
butions. First, given the recent development in the natural gas markets, we adopt a copula-GARCH approach to investigate the conditional dependence structure between the two markets. Precisely, we look at the tails of oil and gas return distributions, and examine both the degree and nature of their dependence at extreme levels conditionally on the possibility of extreme financial events such as the recent global financial crisis. As we subsequently define the co-exceedances as the joint occurrence of extreme negative return or extreme positive return (i.e., values below or above a certain pre-specified threshold), it is straightforward to explore how oil and gas returns are linked to each other during bear and bull market phases. Notice that the study of extreme comovement is an issue of particular importance if one wishes to design suitable diversification stragtegies and to build optimal portfolios of international assets in times of crises. In the past literature, a number of studies have investigated the issues of volatility transmission, correlation dynamics, and contagion effects between international financial markets using various econometric models (e.g., Forbes and Rigobon, 2002; Gilmore et al., 2008; Abad et al., 2010). They generally find evidence that crossmarket correlation is time-varying and that it tends to increase in times of high volatility. Several studies have questioned the joint extreme movements of financial markets around the world (e.g., Longin and Solnik, 2001; Bae et al., 2003; Baur and Schulze, 2005; Christiansen and Ranaldo, 2009) and document asymmetric dependence patterns. To the extent that the oil and natural gas markets are characterized by crises of different sources and pro- 
portions, the copula approach is thus preferred to examine the asymmetry in the tail distributions of these markets, which is not the case for the family of the GARCH models.

Second, our extreme-value copula-GARCH approach allows one to capture nonlinearities in the oil-gas market relationships as well as some empirical stylized facts of their return distributions such as volatility persistence, fat tail behavior and asymmetric impacts of return innovations on volatility (Sadorsky, 2006; Regnier, 2007; Aloui and Jammazi, 2009; Arouri et al., 2011), while avoiding the drawbacks of linear measures of interdependence such as Pearson correlation. Previous studies have recognized the relevance and suitability of copula models in modeling the conditional dependence structure between financial variables (e.g., De Melo Mendes, 2005; Jondeau and Rockinger, 2006; Palaro and Hotta, 2006; Aloui et al., 2011). Moreover, the use of a more recent dataset, spanning the period from January 1997 through October 2011, enables one to account for several periods of long swings in the oil and gas prices, including for example the terrorist attacks on September 11, 2001 and the 2007-2009 global financial crisis which was sparked by the US subprime market failures. Our work is thus broadly related to these studies. However, we differ from them in that we focus on the extreme (tail) dependence of energy markets using a larger set of copula functions. For instance, Jondeau and Rockinger (2006) use the Gaussian and Student- $t$ copulas to examine the dependency between four major stock markets (France, Germany, the United Kingdom, and the United States). 
Palaro and Hotta (2006) discuss the application of conditional copula approach in estimating the market risk of a portfolio composed of the Nasdaq and the S\&P500 stock indices by using the symmetrized Joe-Clayton (SJC), Student- $t$ and Plackett copulas.

Finally, we show the usefulness of the proposed copula-GARCH model in forecasting the market risk exposure of an equally-weighted oil and gas portfolio by examining the out-of-sample accuracy of Value-at-Risk $(V a R)$ forecasts. We are here motivated by the fact that the $V a R$ is nowadays the most widely used risk measure ${ }^{1}$ Over the past decades, it has been shown that risk models based on standard approaches (e.g., historical simulations and GARCH) are not adequate during crisis periods as they mostly fail to anticipate the extreme fluctuations that have realized (Aloui et al., 2013). Even though our article is not concerned by banks' asset portfolios, the application of our mehtodology to improve the internal market risk models of banks and financial institutions is straigtforward.

Using daily global spot prices of the West Texas Intermediate (WTI) crude oil and the Henry Hub natural gas, we find that these oil and gas markets exhibit extreme dependence only during bull markets and that the Husler-Reiss copula is identified as the best model for describing their ex-

\footnotetext{
${ }^{1}$ The VaR has also been an integral part in banks' market risk management operations since being mandated by the Basel I Accord (Basel Committee, 1996), and continuing with Basel II. Recently, the Basel Committee also seeks to increase safety in the international financial system by proposing the Basel III, and investment banks should be involved as much as commercial banks.
} 
treme dependence structure. Our results also indicate that the accuracy of a portfolio's market risk measure such as the $V a R$ is significantly improved when our empirical extreme value copula-GARCH model (EVC-GARCH) is used. The evidence of joint extreme movements when markets go up can be possibly explained by the simultaneous impacts of increasing economic activities. Seemingly, the metaphor that the rising tide lifts all the boats applies here, but the opposite that a dropping tide drops all the boats does not. In an expanding economy, the industrial use of natural gas and the dual conversion capacity between oil and natural gas will increase. However, in a contracting economy the conversion capacity shrinks. Moreover, the industrial use of natural gas shrinks during crises as happened in the last global financial crisis. At time of recessions, major importers particularly in Europe also press for gas prices to be de-linked from oil-indexed long-term supply contracts. Hub prices for natural gas are also not oil-linked prices particularity during recessions. Finally, gas markets require heavy investments for distribution as for liquid natural gas (LNG) and pipelines on long distances with multiple jurisdictions involved, necessitating longer term contracts and constrained their supply during strong economic expansion which is not the case during severe economic recessions.

The remainder of this article is structured as follows. Section 2 provides a review of the literature. Section 3 describes the empirical methodology and the estimation strategy. Section 4 presents the data used and discusses the empirical results. Section 5 provides some concluding remarks. 


\section{Review of the literature}

The dynamic relationship between oil and gas markets has been investigated in the extant literature. Typically, this relationship has been approached by using simple correlations and deterministic trends. For example, Alexander (2004) finds strong correlation between returns on crude oil and natural gas futures contracts, but notes that this correlation cannot be modeled correctly by a bivariate normal distribution because of the potential of nonlinear dependence between the two return series as well as of the asymmetry of their return distributions. Moreover, when data have unit roots, such analysis is faulty and subject to spurious results.

With the advancement in time series econometric techniques, more rigorous analysis has been employed. Serletis and Herbert (1999) investigate the existence of common trends in natural gas prices at the Henry Hub and Transco Zone 6, the price of residual fuel oil at New York Harbor, and electricity prices at PJM (Pennsylvania, New Jersey, Maryland) power markets. Their results from unit roots and cointegration tests indicate that the three fuel prices are cointegrated, and that the Transco Zone 6 natural price adjusts to deviations in the long-run relation significantly faster than do the Henry Hub price. Using the cointegration techniques, Villar and Joutz (2006) find a long-run (equilibrium) relationship between the WTI oil price and the Henry Hub natural gas price. Their bivariate VEC models demonstrate that a permanent shock of $20 \%$ in the WTI price leads to a $16 \%$ increase in the Henry Hub price. Hartley et al. (2008) employ a similar approach to exam- 
ine the presence of a stable long-run relationship between the WTI crude oil and Henry Hub prices, indentify the shocks that cause a departure from this relative relationship and estimate the time it takes to re-establish it in the long-run. Short-run deviations could be related to weather shocks, supply disruptions and changes in storage. These authors conclude that the narrowing of the long-run relative relationship is due to technical factors related to the use of natural gas in the generation of electricity in place of oil based fuels. In a related study, Brown and Yucel (2007), using an error-correction model, show that when the weather conditions, inventory trends and other additional factors are taken into consideration, the movements in crude oil prices have a prominent role in shaping natural gas prices. Their findings imply a continuum of prices at which natural gas and petroleum products are substitutes. Benth and Kettler (2011) use a bivariate non-symmetric copula to model the evolution of electricity and natural gas prices in the United Kingdom and find that options prices are significantly influenced by the copula and the marginal distributions, along with the seasonality of the underlying prices.

To the best of our knowledge, the study of Grégoire et al. (2008) is the sole contribution in the related literature that models the oil and natural gas price dependence using the copula models. They document that the Student$t$ copula provides the best fit to the oil-gas bivariate dependence structure. However, they have not examined the issue of extreme dependence as well as the implications of their results for market risk assessment as in our study. 
In another research, Accioly and Aiube (2008) use the copula approach to investigate the dependence between prices of crude oil and gasoline over two periods. They find dependence between the two prices in the first period (May 1990 - December 2003) but this dependence increased in the recent second period (January 2004 - September 2008).

\section{Empirical methodology}

After a brief description of copula functions, we introduce the empirical model for the margins of the return distributions as well as the estimation procedure.

\subsection{Copulas and dependence}

Copulas have become increasingly popular in finance over the past decade. They have been applied to the investigation of the dependence structure between various financial markets (e.g., Chan-Lau et al., 2004; Jondeau and Rockinger, 2006; Ning, 2010; Aloui et al., 2011; Choe and Jang, 2011; Aloui et al., 2013). Previous studies show that copula functions provide a flexible and efficient way to model correlated multivariate data because it is relatively easy to construct a multivariate joint distribution from marginal univariate distributions and to select the best copula function to examine the dependence structure between the variables. ${ }^{2}$

\footnotetext{
${ }^{2}$ The interested readers may refer to Jondeau and Rockinger (2006), and Palaro and Hotta (2006), among others, for more details on the copula theory and its applications to VaR estimations.
} 
A copula function is defined as a multivariate probability distribution $C$ for which the marginal probability of each variable is uniformly distributed (Joe, 1996). A 2-dimensional copula is therefore suitable for our modeling purpose of the dependence structure between the crude oil and natural gas markets. According to the Sklar's theorem, the joint distribution $H$ of two random variables, $X$ and $Y$, with marginal distributions, $F$ and $G$, can be described by a copula function $C:[0,1]^{2} \rightarrow[0,1]$ such that

$$
H(x, y)=C(F(x), G(y))
$$

If $F$ and $G$ are continuous, then $C$ is unique. Otherwise, $C$ is uniquely determined on Range $F \times$ Range $G$. On the other hand, if $C$ is a copula and $F$ and $G$ are distribution functions, then the function $H$ defined above is a joint distribution with margins $F$ and $G ?^{3}$

In addition to the dependence parameter that will be determined in accordance with the copula in use, we can derive the dependence in the tails of the distribution (the upper and the lower tail dependence coefficients) in order to measure the probability that markets crash or boom together. Then the coefficient of lower tail dependence $\lambda_{L}$ is

$$
\lambda_{L}=\lim _{t \rightarrow 0^{+}} \operatorname{Pr}\left[Y \leq G^{-1}(t) \mid X \leq F^{-1}(t)\right]
$$

\footnotetext{
${ }^{3}$ See Joe (1997) and Nelsen (1999) for detailed discussions of copulas functions and their properties.
} 
which quantifies the probability of observing a lower $Y$ assuming that $X$ is lower itself. In the same way, the coefficient of upper tail dependence $\lambda_{U}$ can be defined as

$$
\lambda_{U}=\lim _{t \rightarrow 1^{-}} \operatorname{Pr}\left[Y>G^{-1}(t) \mid X>F^{-1}(t)\right]
$$

The tail dependence coefficients (TDC) can also be explicitly expressed in terms of copula. If $C$ is a copula of $(X, Y)$, then

$$
\lambda_{L}=\lim _{t \rightarrow 0^{+}} \frac{C(t, t)}{t} \quad \text { and } \quad \lambda_{U}=\lim _{t \rightarrow 1^{-}} \frac{1-2 t+C(t, t)}{1-t}
$$

The symmetric tail dependence between two markets cannot be rejected when the lower tail dependence coefficient equals the upper one. Otherwise, the tail dependence is asymmetric. It is worth noting that the tail dependence coefficients provide a way for ordering copulas. One would say that copula $C_{1}$ is more concordant than copula $C_{2}$ if $\lambda_{U}$ of $C_{1}$ is greater than $\lambda_{U}$ of $C_{2}$.

To the extent that we are interested in modeling the joint extreme behavior of the oil and gas markets, the copula models we consider fall into the family of extreme value copulas. They are briefly presented below.

The Gumbel copula is an asymmetric copula with higher probability concentrated in the right tail (Gumbel, 1960). It is given by

$$
C(u, v)=\exp \left\{-\left[(-\ln u)^{\theta}+(-\ln v)^{\theta}\right]^{1 / \theta}\right\}
$$

where the dependence parameter $\theta$ can take any value in $(1,+\infty)$.

The Tawn Copula, also called the mixed model of the Gumbel and inde- 
pendence copula, is an extreme value copula expressed as

$$
C(u, v)=u v \exp \left\{-\theta \frac{\ln u \ln v}{\ln (u v)}\right\}, 0 \leq \theta \leq 1
$$

The Galambos copula introduced by Galambos (1975) is

$$
C(u, v)=u v \exp \left\{\left[(-\ln u)^{-\delta}+(-\ln v)^{-\delta}\right]^{-1 / \delta}\right\}, \quad 0 \leq \delta<\infty
$$

The Husler-Reiss copula introduced by Husler and Reiss (1987) has the following form:

$$
C(u, v)=\exp \left\{-\widetilde{u} \phi\left[\frac{1}{\delta}+\frac{1}{2} \delta \ln \left(\frac{\widetilde{u}}{\widetilde{v}}\right)\right]-\widetilde{v} \phi\left[\frac{1}{\delta}+\frac{1}{2} \delta \ln \left(\frac{\widetilde{v}}{\widetilde{u}}\right)\right]\right\}, \quad 0 \leq \delta \leq \infty
$$

where $\phi$ is a cumulative distribution function (CDF) of a standard Gaussian distribution, $\widetilde{u}=-\ln (u)$ and $\widetilde{v}=-\ln (v)$.

Extreme-value copulas are a convenient choice to model data with positive dependence in the tails. It can be shown (Pickands, 1981) that the extreme value copulas can be represented in terms of a real-valued function $A$ on the interval $[0,1]$ by

$$
C(u, v)=\exp \left\{\log (u v) A\left(\frac{\log (v)}{\log (u v)}\right)\right\}
$$

where $A$ is convex function that satisfies $\max (t, 1-t) \leq A(t) \leq 1$ for all $t$ in $[0,1]$ and that is usually referred to the Pickands dependence func- 
tion. The upper and lower bounds of $A$ correspond to independence and the comonotone copula, respectively. The Gumbel-Hougaard copula, introduced by Gumbel (1960), is the only copula that is at the same time Archimedean and extreme-value. It is an asymmetric copula with higher probability concentrated in the right tail. The degree of the dependence ranges from independence $(\theta=1)$ to perfect positive dependence $(\theta=\infty)$. The Tawn copula model, dating back to Tawn (1988), adds more flexibility to the Gumbel family of copulas. The amount of dependence ranges from independence $(\theta$ $=0)$ to perfect positive dependence $(\theta=1)$. Also, the Galambos and the Husler-Reiss copulas allow for greater dependence in the upper tail of the distribution. The parameter of dependence $\delta$ can take values from 0 to $\infty$, which imply independence and perfect positive dependence, respectively.

We also consider the Survival Clayton copula, which can be viewed as a mirror image of the density of the Clayton copula. It is derived from the Clayton copula as

$$
C(u, v)=u+v-1+\left((1-u)^{-\theta}+(1-v)^{-\theta}-1\right)^{-1 / \theta}, \theta \in[-1, \infty) \backslash\{0\}
$$

\subsection{Estimation procedure}

We combine the copula functions with a GARCH-type model of conditional heteroscedasticity to investigate the extreme dependence between the crude oil and natural gas markets. A standard ARMA-GARCH model is used as a filter to get approximately i.i.d data for estimating the copula func- 
tions, given its suitability for capturing the stylized facts in financial returns including mean reversion and seasonality in commodity markets. The two commonly-used information criteria, AIC and BIC, select the $\operatorname{ARMA}(1,0)$ GARCH $(1,1)$ specification with Student-t distribution for the oil return series, and the $\operatorname{ARMA}(3,0)-\operatorname{GARCH}(1,1)$ specification with Student-t distribution for the natural gas return series. This combined modeling approach is thus advantageous in that it offers the possibility to separately model the margins and the dependence structure of the two markets under consideration.

Once the univariate GARCH(1,1) model of Bollerslev (1986) is estimated for crude oil and natural gas returns, we extract the filtered residuals and construct their marginal distributions by fitting the Generalized Pareto Distribution (GPD) to the upper and lower tails of the standardized filtered residuals. Following De Melo Mendes (2005), we set the threshold values such that $10 \%$ of the residuals are reserved for the lower left and $10 \%$ of the residuals for the upper right tails, i.e., the empirical $10 \%$ and $90 \%$ quantiles in each margin. Similar to Longin and Solnik (2001), we interpret the tail dependence coefficient which describes how large (respectively, small) returns of a return series occur with large (respectively, small) returns of another series to as extreme dependence during bull (respectively, bear) markets.

We then generate uniform variates by plugging the GPD parameter estimates into the GPD distribution function, and employ the method proposed by Joe and Xu (1996), called inference functions for margins (IFM), to fit se- 
lected copulas to the created uniform variates. Notice that the IFM method determines, in the first stage, the margin parameters by performing the estimation of the univariate marginal distributions as

$$
\begin{aligned}
& \widehat{\alpha_{x}}=\underset{\alpha_{x}}{\arg \max } \sum_{i=1}^{n} \log f_{1}\left(X_{i} ; \alpha_{x}\right) \\
& \widehat{\alpha_{y}}=\underset{\alpha_{y}}{\arg \max } \sum_{i=1}^{n} \log f_{2}\left(Y_{i} ; \alpha_{y}\right)
\end{aligned}
$$

In the second stage, given estimates $\widehat{\alpha_{x}}$ and $\widehat{\alpha_{y}}$, the unknown dependence parameter of the copula $\theta$ is determined as

$$
\widehat{\theta}=\underset{\theta}{\arg \max } \sum_{i=1}^{n} \ln c\left(F_{1}\left(x_{i} ; \widehat{\alpha_{x}}\right), F_{2}\left(y_{i} ; \widehat{\alpha_{y}}\right) ; \theta\right)
$$

As noted by Joe and Xu (1996), the IFM relies on the fundamental concept of the copula theory by separating the estimation of the marginal parameters from that of the copula dependence parameter. This approach is computationally less intensive than the maximum likelihood estimation (MLE) method. It is also more attractive than the canonical maximum likelihood (CML) approach because it enables one to obtain the full parametric description of marginal distributions, while the CML approximates the true and unknown parametric marginals with their empirical cumulative distribution functions. Moreover, the IFM estimator also verifies the property of 
asymptotic normality such as

$$
\sqrt{n}\left(\widehat{\eta}_{I F M}-\eta_{0}\right) \underset{d}{\rightarrow} N(0, V)
$$

and the asymptotic covariance matrix for $\widehat{\eta}_{I F M}$ is

$$
V=\left(-D_{g}^{-1}\right) M_{g}\left(-D_{g}^{-1}\right)^{\prime}
$$

where $M_{g}=\operatorname{Cov}(g(Z ; \eta))=E\left[g g^{\prime}\right], D_{g}=E\left[\partial g(Z, \eta) / \partial \eta^{\prime}\right]$ with $Z=(X, Y)$ and $g^{\prime}=\left(\partial l_{1} / \partial \alpha_{x}^{\prime}, \partial l_{2} / \partial \alpha_{y}^{\prime}, \partial l / \partial \theta^{\prime}\right)$ with $l_{k}=\log f_{k}(. ; \alpha)$ for $k=1,2$ and $l=\log f(. ; \eta) \cdot !^{4}$

Before presenting the goodness-of-fit tests used to compare copula models, we briefly introduce the notion of the empirical copula developed by Deheuvels (1978). Let $\left(x_{i}, y_{i}\right)$ be an i.i.d sample from a continuous bivariate random variables with size equal to $n$ and $x_{(i)}, y_{(j)}, 1 \leq i, j \leq n$ denote the order statistics from the sample. Then, the empirical copula $C_{n}$ is the function

$$
C_{n}\left(\frac{i}{n}, \frac{j}{n}\right)=\frac{1}{n} \sum I_{\left\{x_{k} \leq x_{(i)}, y_{k} \leq y_{j}\right\}}
$$

where $I$ denotes the indicator function. As proved by Deheuvels (1978), the empirical copula $C_{n}$ converges uniformly to the underlying copula $C$ when $n \rightarrow \infty$. The empirical copula frequency $c_{n}$ defined by Nelsen (1999) is given

\footnotetext{
${ }^{4}$ Further details regarding the applications of the IFM method can be found in Joe (2005).
} 
by

$$
c_{n}\left(\frac{i}{n}, \frac{j}{n}\right)=\left\{\begin{array}{l}
\frac{1}{n}, \text { if }\left(u_{(i)}, v_{(i)}\right) \text { is an element of the sample } \\
0, \text { otherwise }
\end{array}\right.
$$

The empirical copula $C_{n}$ can help us select the adequate copula model through the distance between the fitted copula and the empirical one. The two goodness-of-fit tests used in this article are introduced by Genest et al. (2006, 2011). They are respectively based on the empirical copula and on the Pickands dependence function, and the Cramér-Von Mises distances are used to compute the test statistics as

$$
S_{n}=n \int\left\{C_{n}(u, v)-C_{\theta_{n}}(u, v)\right\}^{2} d C_{n}(u, v)
$$

and

$$
M_{n}=\int_{0}^{1} n\left|A_{n}(t)-A_{\theta_{n}}(t)\right|^{2} d t
$$

More specifically, the first statistic $S_{n}$ measures how close the fitted copula $C_{\theta_{n}}$ is to the empirical copula $C_{n}$. The second statistic $M_{n}$ measures the distance between a nonparameteric rank-based estimator of the Pickands dependence function $A_{n}$ and a parametric estimation $A_{\theta_{n}}$ of $A$. Large values of the computed test statistics lead to reject the null hypothesis that the estimated copula belongs to an empirical copula family (i.e., the copula in use does not provide best fit to the data). Note that the $p$-values associated 
with the first test are computed using a multiplier approach as described in Kojadinovic and Yan (2010). The second test is applied only for an extreme value copula since it can be expressed in the form of the Pickands dependence function. The $p$-values associated with this test are computed using the parametric bootstrap.

\section{Data and results}

\subsection{Data and descriptive statistics}

Our dataset contains daily closing spot prices of global benchmark WTI crude oil and Henry Hub natural gas over the period from January 8, 1997 to October 04, 2011. The time-variations of spot prices are plotted in Figure1. While those prices of both crude oil and natural gas share several large swings in common, they tend to behave differently over the study period. On the one hand, the natural gas price is influenced in the short-run by short-lived factors such as weather condition, changes in inventories and interruption in supply. On the other hand, the oil market is global, while that of the natural is regional. Any important event or cause occurring whether in Nigeria, the Middle East or the Gulf of Mexico, becomes a global shock and would affect first and foremost the oil market. It is also possible that the oil market is more sensitive to arbitrage activity because of being a global market, which implies more efficiency. Some common peaks are however observed at the end of 2001, at the beginning of 2003, at the end of 2006, and at the mid2008. Major shocks such as the 2003 Iraq war also affect both markets, but 


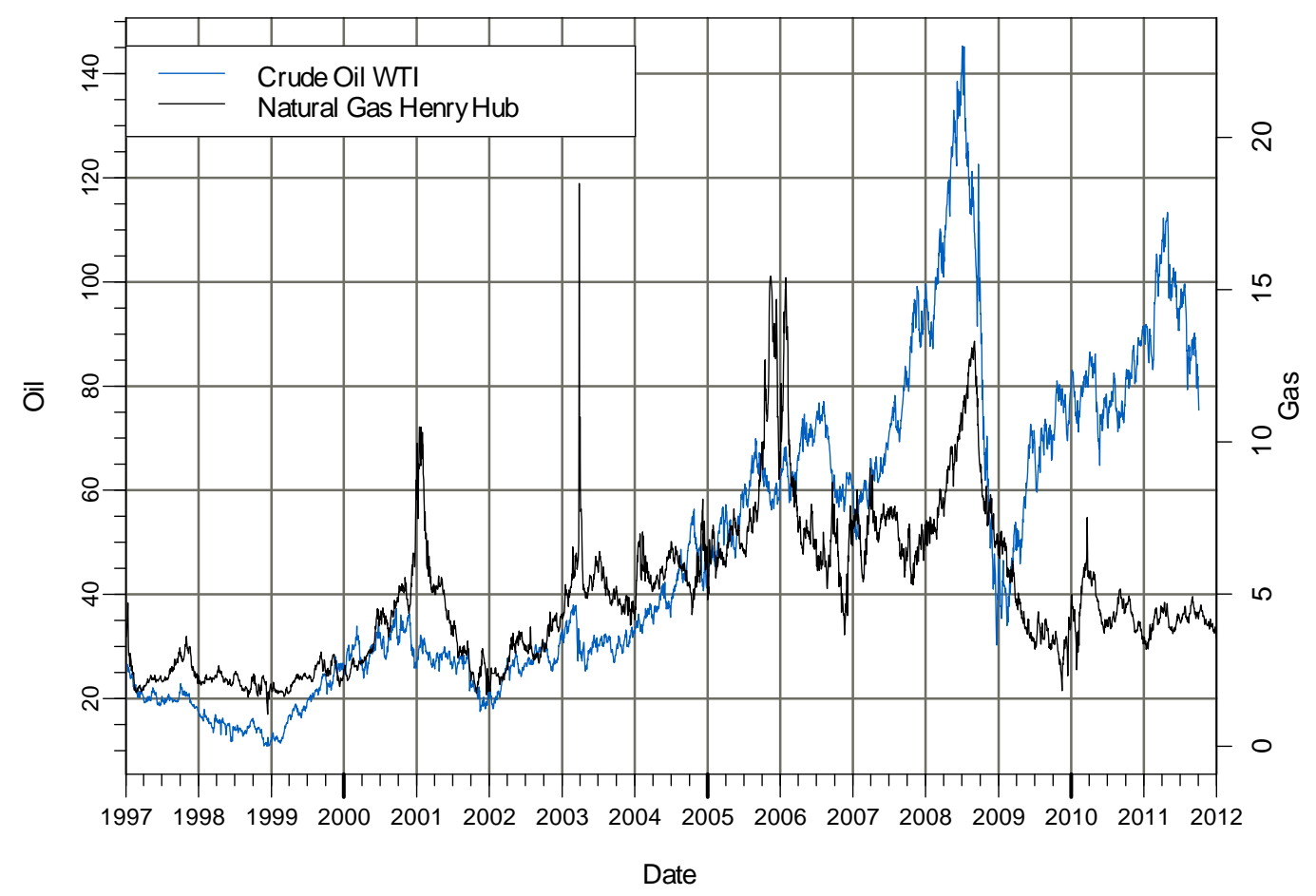

Figure 1: Henry Hub natural gas and WTI crude oil prices

by different magnitudes.

Data are expressed in US dollars and obtained from the US Energy Information Administration (EIA). We compute the returns of the WTI crude oil and the Henry Hub natural gas by taking the difference in the logarithm of two consecutive daily prices. The time-paths of the return series are plotted in Figure 2, They show the occurrence of some extremely large and small 

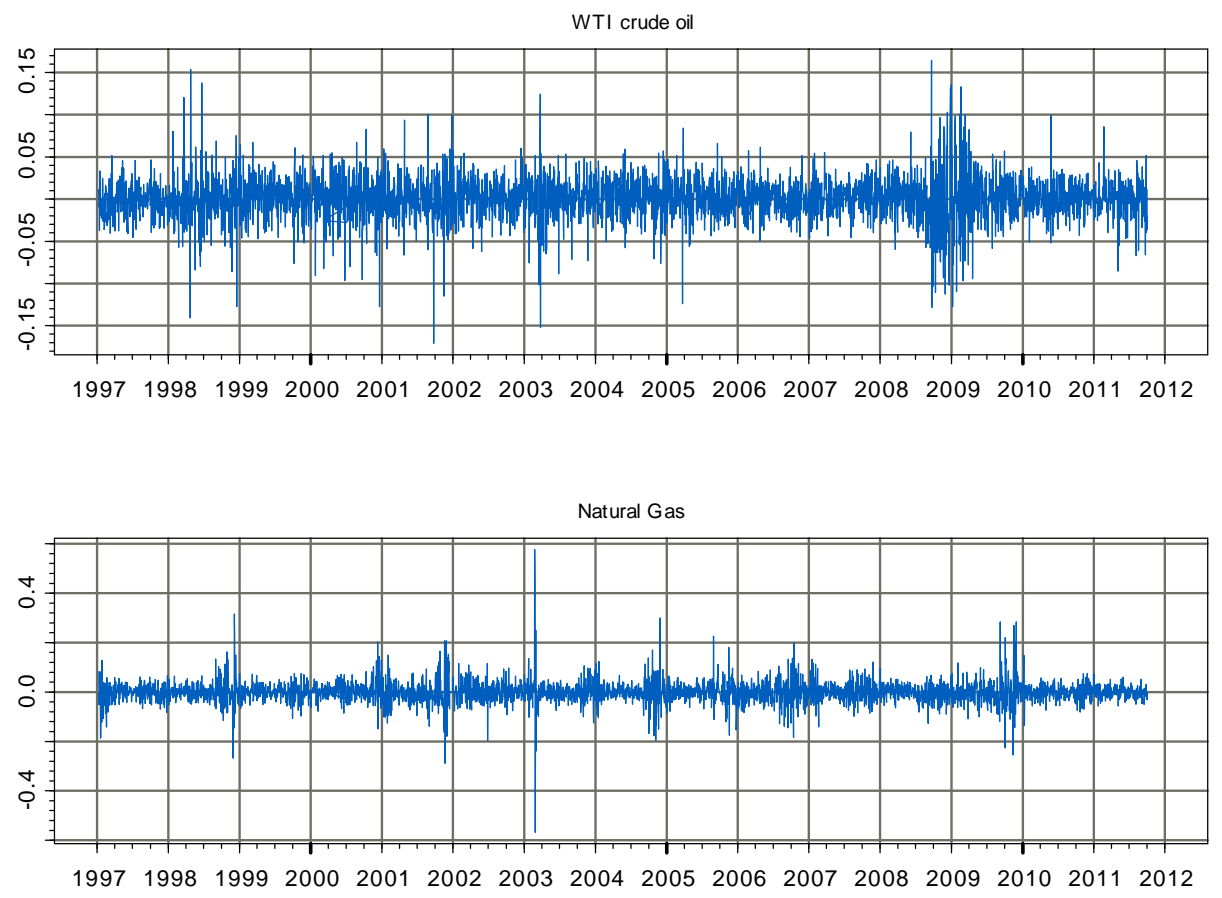

Figure 2: Daily returns of crude oil and natural gas from 01/07/1997 to 10/04/2011 

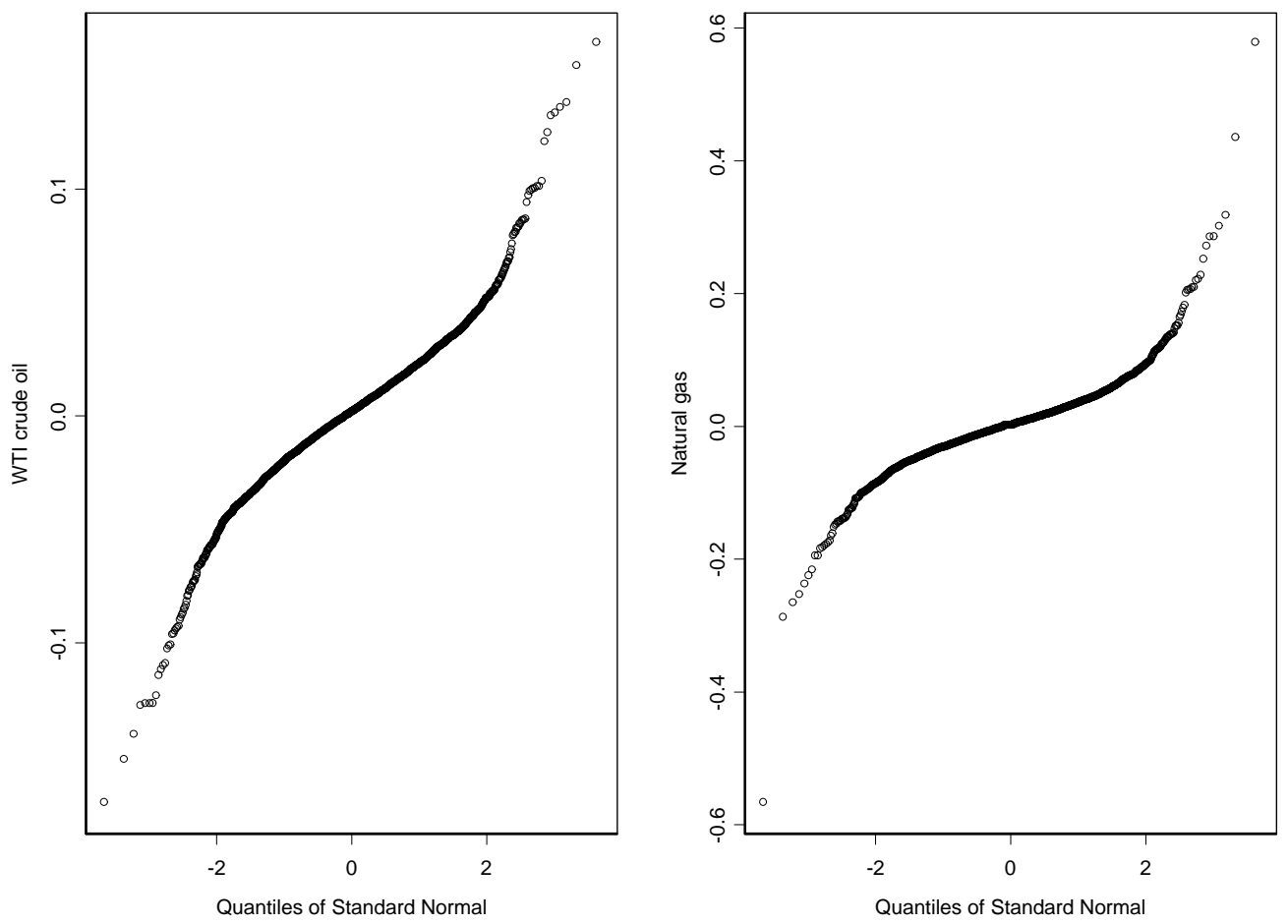

Figure 3: Normal QQ-plots of the daily log returns of crude oil and natural gas 
returns for both markets. Descriptive statistics and distributional characteristics of return series are reported in Table 1. The average return is positive for the WTI crude oil market, but negative for the natural gas market. The natural gas returns have been affected by the discovery of the hydraulic fracturing technique which has multiplied the reserves in the United States. The unconditional volatility of the crude oil market as measured by standard deviation is, however, about five times larger than that of the natural gas market, due to the reasons provided earlier.

Daily returns are negatively and positively skewed for crude oil and natural gas markets respectively, indicating that it is more likely to observe large negative returns of the crude oil market, but large positive returns of the natural gas market. Both return series are leptokurtically distributed in view of significant excess kurtosis. These findings clearly show that both return series depart from normality and that the probability of extremely negative and positive realizations for each of the crude oil and natural gas returns is thus higher than that of a normal distribution. The departure from normality is confirmed by the Jarque-Bera test and the QQ-plots of the returns against the normal distribution (see, Figure 3). We also perform the Ljung-Box Q-statistics of order 12 for raw and squared returns. The results indicate that the null hypothesis of no autocorrelation is rejected at the $1 \%$ level for both markets. The results of the Lagrange Multiplier test for conditional heteroscedasticity point to the presence of the $\mathrm{ARCH}$ effects in the return data, thus supporting our decision to use a GARCH model to filter the 
daily returns. Finally, the null hypotheses that return series have unit roots are clearly rejected as the ADF test statistics are less than critical values. Thus, the logarithmic return series are all stationary at the $1 \%$ significance level.

Table 1: Descriptive statistics for daily oil and natural gas returns

\begin{tabular}{|l|c|c|}
\hline Statistics & Crude oil market & Natural gas market \\
\hline Mean & $2.852 \mathrm{e}-04$ & $-1.91 \mathrm{e}-05$ \\
\hline Min & -0.171 & -0.568 \\
\hline Max & 0.164 & 0.577 \\
\hline Std. Dev. & 0.026 & $4.617 \mathrm{e}-02$ \\
\hline Skewness & -0.166 & 0.487 \\
\hline Excess kurtosis & 4.496 & 19.884 \\
\hline Q(12) & $35.433^{*}$ & $177.913^{*}$ \\
\hline$Q^{2}(12)$ & $783.241^{*}$ & $1863.573^{*}$ \\
\hline Jarque Bera & $3122.177^{*}$ & $60926.967^{*}$ \\
\hline ARCH(12) & $342.843^{*}$ & $1201.649^{*}$ \\
\hline ADF & $-18.63^{*}(12)$ & $-18.71^{*}(10)$ \\
\hline
\end{tabular}

Notes: This table displays summary statistics for daily crude oil and natural gas returns. The sample period is from January 8, 1997 to October 04, 2011. The statistics $Q(12)$ and $Q^{2}(12)$ are the empirical statistics of the 12-order Ljung-Box tests for serial correlation in returns and squared returns. JB is the empirical statistic of the Jarque-Bera test for normality. $A R C H(12)$ is the Lagrange Multiplier test for autoregressive conditional heteroskedasticity. ADF is the augmented Dickey-Fuller test for unit root. The lag length for the ADF test (values within brackets) is selected using the procedure of $\mathrm{Ng}$ and Perron (2001). * indicates the rejection of the null hypotheses of no autocorrelation, normality, homoscedasticity and unit root at the $1 \%$ level. 


\subsection{Empirical results}

We first estimate the selected ARMA-GARCH models for the return data using the maximum likelihood estimation (MLE) method..$^{5}$ Figure 4 shows the ACF of the standardized residuals, obtained from the GARCH fit. When compared to the ACFs of the raw returns, it can be easily seen that the standardized residuals are approximately identically and independently distributed. We also perform the $\mathrm{ARCH}$ test on the estimated residuals and find no evidence of remaining $\mathrm{ARCH}$ effects.6.$^{6}$ These findings thus suggest that the $\operatorname{GARCH}(1,1)$ specification is flexible enough to deal with conditional heteroscedasticity, and that the estimated residuals are much more suitable for the GPD tail estimation.

We then turn to estimate the copula functions for crude oil and natural gas returns, given the availability of the estimates of univariate GARCH models. For this purpose, we extract the filtered residuals from each return series, and estimate the marginal distribution of each series by applying the GPD to the residuals that fall into the upper and lower tails. As noted earlier, fitting the GPD to the filtered returns in each tail requires the specification of the lower and upper thresholds. In this paper, we set the threshold values such that $10 \%$ of the residuals are reserved for each tail.

\footnotetext{
${ }^{5}$ The selected empirical specifications for the oil and natural gas returns are the $\operatorname{ARMA}(1,0)-\operatorname{GARCH}(1,1)$ and the $\operatorname{ARMA}(3,0)-\operatorname{GARCH}(1,1)$, respectively. The estimation results are not reported in order to conserve space, but are entirely available upon request addressed to the corresponding author.

${ }^{6}$ The full results of ARCH tests can be made entirely available upon request to the corresponding author.
} 
To effectively assess the GPD fit for the tails of the distributions, we show in Figure 5 the QQ-plots of the empirical CDF of the upper and lower tail exceedances against the empirical quantiles obtained from the GPD fit. The approximate linearity of these plots indicates that the fitted distributions closely follow the exceedance data, so the GPD model seems to be a good choice.

Figure 6 displays the scatterplot of the filtered return series in four quadrants. The joint behavior of the data witnesses some extreme comovements in the lower left and upper right quadrants. The estimates of the dependence parameter $\theta$ associated with the five copula functions we consider (i.e., the Gumbel, Tawn, Galambos, Husler Reiss and survival Clayton) are reported in Table 2, These estimates are, as expected, highly significant for all copula functions under consideration, thus underlying the presence of joint dependence between the two returns. This finding indicates that the extreme events or crises are likely to spread from one market to another during the bull periods. Table 2 also reports the $p$-values of the two goodness-of-fit tests discussed above for both positive and negative co-exceedances as defined in Equations (14) and (15). We note that the Husler Reiss copula provides the best fit to the data during bull markets, followed by the Galambos copula and the Gumbel copula. The Tawn copula is rejected by both tests at the $5 \%$ level. In Figure 7, we plot a contour of the level sets of the Husler Reiss copula and its associated empirical copula. The fact that the two graphs follow closely together confirms that the Husler Reiss copula is the best model 
WTI Crude oil

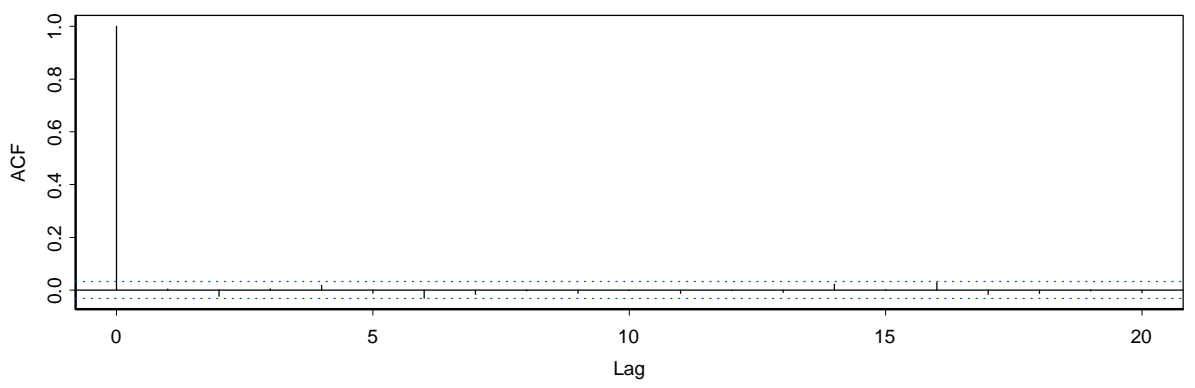

Natural Gas

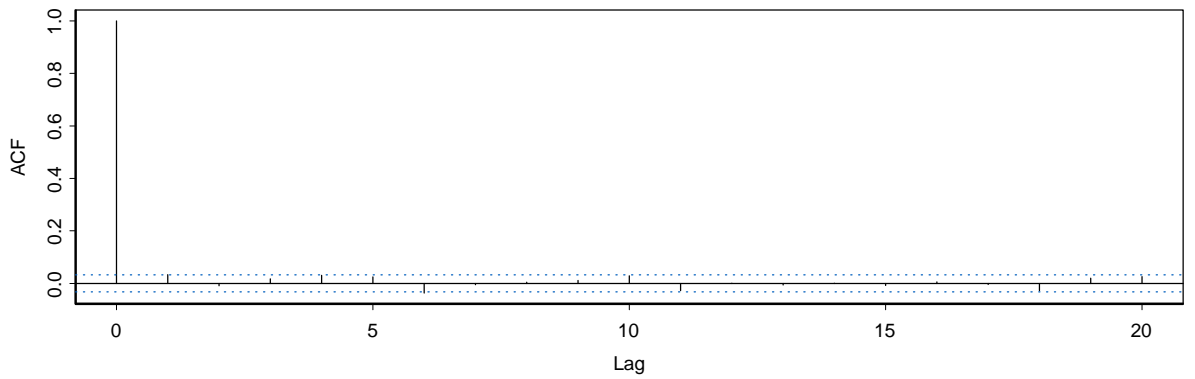

Figure 4: ACF of the standardized residuals

for describing the extreme comovement between the crude oil and natural gas markets.

For the joint occurrence of extreme losses (bear markets), the results of the goodness-of-fit tests reject all copula models at the $1 \%$ level. It turns out that the fitted copula models are not better than the independence copula, and that the hypothesis of extreme dependence between the two considered markets during bearish periods is rejected. Therefore, our results provide evidence of an asymmetric dependence structure between the crude oil and natural gas markets as they tend to comove during bullish periods, but not 

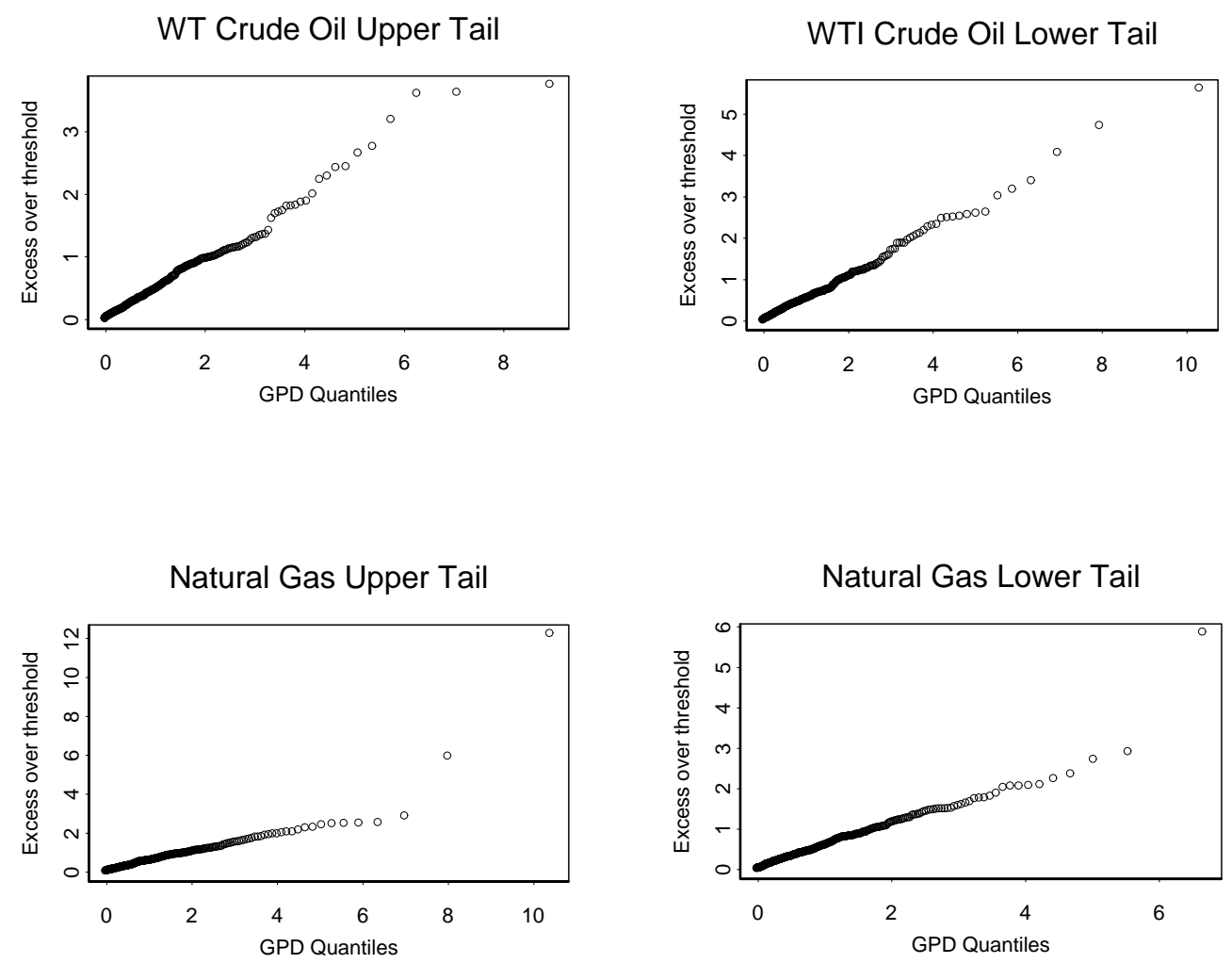

Figure 5: QQ-plot of the upper and lower tail exceedances and empirical quantiles of the GPD fit 
Table 2: Copula parameters, tail dependence coefficients and goodness-of-fit test results for dependent positive and negative co-exceedances

\begin{tabular}{|c|c|c|c|c|}
\hline \multicolumn{5}{|c|}{ Panel A - Positive co-exeedances } \\
\hline & $\theta$ & Upper tail & $M_{n}$ & $S_{n}$ \\
\hline Gumbel & $\begin{array}{c}1.048^{*} \\
(0.012)\end{array}$ & 0.063 & $\begin{array}{l}1.049 \\
{[0.148]}\end{array}$ & $\begin{array}{l}0.032 \\
{[0.097]} \\
\end{array}$ \\
\hline Tawn & $\begin{array}{c}0.097^{*} \\
(0.027)\end{array}$ & 0.048 & $\begin{array}{l}0.617 \\
{[0.003]}\end{array}$ & $\begin{array}{l}0.068 \\
{[0.002]} \\
\end{array}$ \\
\hline Galambos & $\begin{array}{c}0.250^{*} \\
(0.083)\end{array}$ & 0.062 & $\begin{array}{l}0.162 \\
{[0.271]}\end{array}$ & $\begin{array}{l}0.028 \\
{[0.163]} \\
\end{array}$ \\
\hline Husler Reiss & $\begin{array}{c}0.533^{*} \\
(0.025) \\
\end{array}$ & 0.061 & $\begin{array}{l}0.157 \\
{[0.295]} \\
\end{array}$ & $\begin{array}{c}0.0278 \\
{[0.190]} \\
\end{array}$ \\
\hline Survival Clayton & $\begin{array}{c}0.101^{*} \\
(0.020)\end{array}$ & 0.001 & - & $\begin{array}{c}0.0286 \\
{[0.168]}\end{array}$ \\
\hline \multicolumn{5}{|c|}{ Panel B - Negative co-exeedances } \\
\hline & $\theta$ & Lower tail & $M_{n}$ & $S_{n}$ \\
\hline Gumbel & $\begin{array}{c}1.037^{*} \\
(0.011)\end{array}$ & 0.049 & $\begin{array}{c}1.358 \\
{[4.995 e-04]}\end{array}$ & $\begin{array}{l}0.075 \\
{[0.001]} \\
\end{array}$ \\
\hline Tawn & $\begin{array}{c}0.093^{*} \\
(0.027)\end{array}$ & 0.046 & $\begin{array}{c}1.631 \\
{[4.995 e-04]}\end{array}$ & $\begin{array}{l}0.087 \\
{[0.005]}\end{array}$ \\
\hline Galambos & $\begin{array}{c}0.225^{*} \\
(0.068)\end{array}$ & 0.046 & $\begin{array}{c}1.428 \\
{[4.995 e-04]}\end{array}$ & $\begin{array}{l}0.079 \\
{[0.003]} \\
\end{array}$ \\
\hline Husler Reiss & $\begin{array}{c}0.494^{*} \\
(0.029)\end{array}$ & 0.043 & $\begin{array}{c}1.452 \\
{[4.995 e-04]}\end{array}$ & $\begin{array}{l}0.080 \\
{[0.001]} \\
\end{array}$ \\
\hline Survival Clayton & $\begin{array}{c}0.063^{*} \\
(0.019)\end{array}$ & $1.653 \mathrm{e}-05$ & - & $\begin{array}{l}0.100 \\
{[0.002]}\end{array}$ \\
\hline
\end{tabular}

Notes: This table presents the copula parameter's estimates, the tail dependence coefficients and the goodness-of-fit test statistics for dependent positive and negative coexceedances. Standard errors are given in parenthesis. P-values associated with statistical tests are given in brackets. 


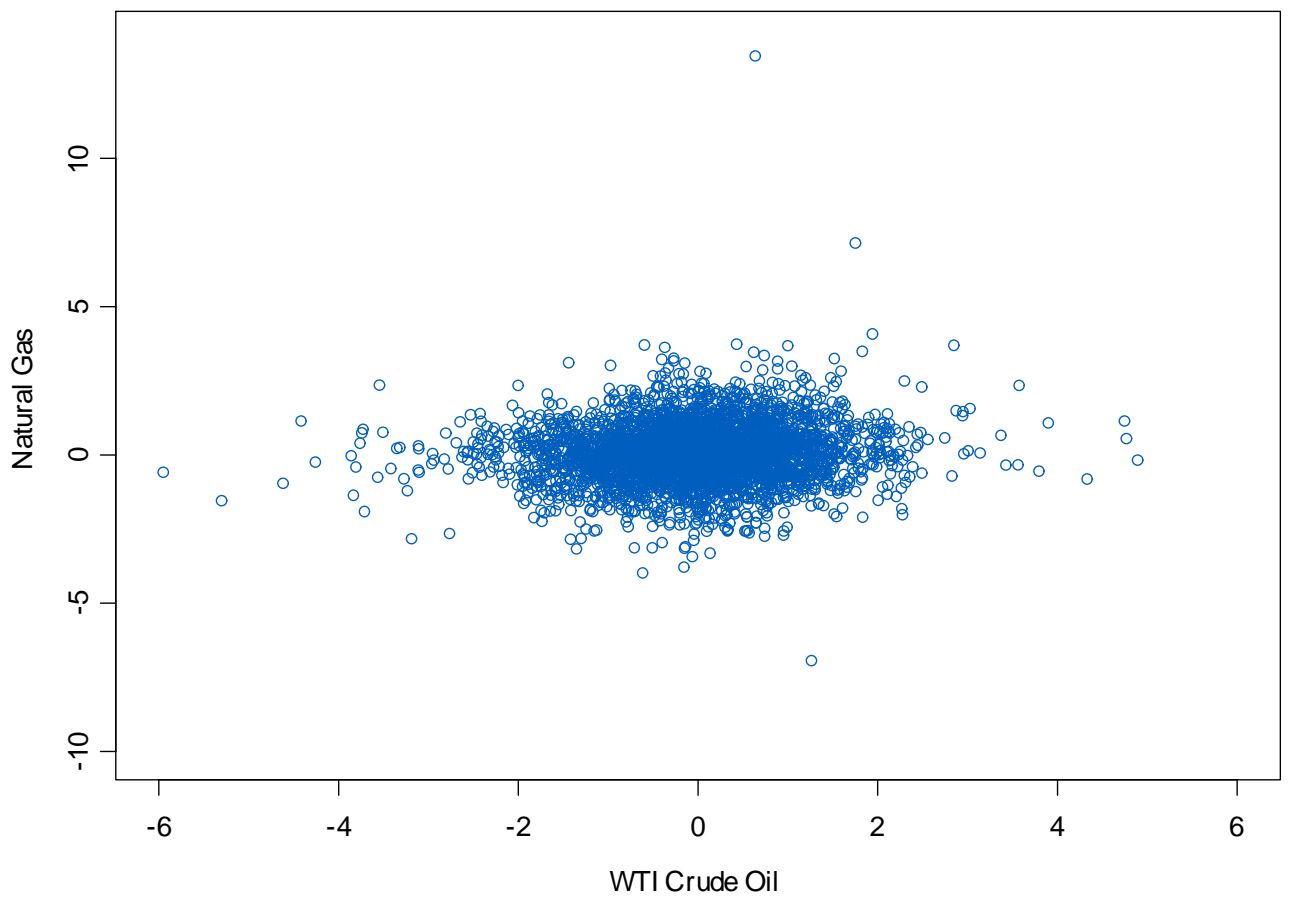

Figure 6: The scatterplot of filtered returns of oil and natural gas 


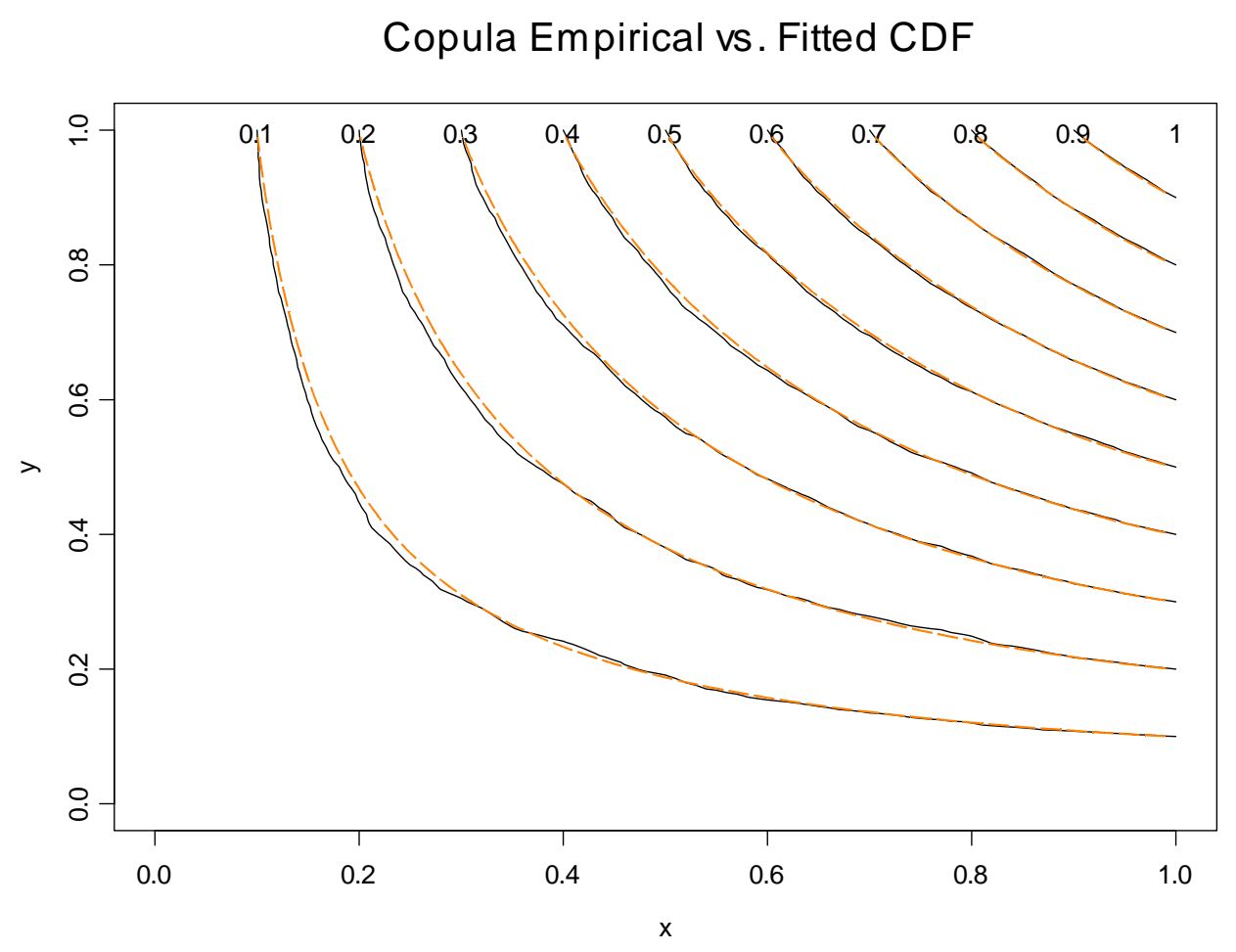

Figure 7: Contour plots of the Husler Reiss copula and the empirical copula 
during bearish periods.

The fact that arbitrageurs are more active in taking advantage of profit opportunities during bull markets than during bear markets is a potential explanation of the results. Consumers also react faster to higher oil and natural gas prices than to lower prices of these commodities because the expenditures on those goods are discretionary.

A more potent explanation points to the importance of the level of economic growth. Strong economic growth manifests itself in stronger demand for all fuel types in the economy which all tend to move up together as rising tides lift all boats as explained earlier. However, contrary to the bull periods, extreme events or crises seem unlikely to spread from one market to another during bear periods, given low economic growth and low energy demand. It is worth noting that the industrial use of natural gas shrinks during crises as happened in the last global financial crisis. Manifestly, major importers particularly in Europe press for natural gas prices to be de-linked from oilindexed long-term supply contracts during times of recessions. Henry Hub prices for natural gas are also not oil-linked prices particularly during recessions.

Finally, gas markets require heavy investments for distribution as for liquid natural gas and pipelines on long distances with multiple jurisdictions involved, necessitating longer term contracts and constrained their supply during strong economic expansion which is not the case during severe economic recessions. 


\subsection{Market risk forecasting with extreme value copula approach}

In a world characterized by fast changes, uncertainties and wide fluctuations, risk measurements and management have become an imperative task as well as an integral part of the operations of banking and financial institutions. The recent financial crises have definitively emphasized a need for a better understanding of risk and its quantification. It is now common that the Value-at-Risk $(\mathrm{VaR})$ is the most widely used risk measure among the

many existing risk measures. Since 1996, the Basel Committee on Banking Supervision establishes the $V a R$ as the official measure of market risk for banking institutions and requires the latter to determine the minimum capital requirements from their own $V a R$ estimates. Adjustments to the $V a R$ models are however necessary as they mostly fail to capture the fat-tail behavior of stock returns and extreme market comovements during crisis times. In addition, $V a R$ backtesting plays a significant role as it allows risk managers to check whether the risk models used are able to properly capture the underlying risk of financial portfolios.

This section shows how the proposed extreme value copula-GARCH model can improve the accuracy of market risk forecasts for an equally-weighted oil and natural gas portfolio. We indeed consider the Value-at-Risk $(V a R)$ as the portfolio's market risk measure and estimate it using Monte Carlo simulations, instead of the analytical method that is only valid for Gaussian copula models. It is worth noting that when copula functions are used to gauge the dependence structure between two variables, it is relatively easy to 
construct and simulate random scenarios from their joint distribution, based on any choice of marginals and any type of dependence structure.

The Monte Carlo method for computing the $V a R$ requires the following steps. First, we simulate dependent uniform variates from the best fitting copula model and transform them into standardized residuals by inverting the semi-parametric marginal CDF of each variate. We then compute the simulated return series for each asset (crude oil and natural gas) using the simulated standardized residuals as well as the GARCH volatility parameters and the conditional observed mean term of the original return series. Finally, the simulated return series of the oil and gas portfolio $R_{t}$ and the portfolio's $V a R$ for a given confidence level $\alpha$ are determined respectively as follows

$$
\begin{gathered}
R_{t}=\log \left(\lambda_{1} e^{x_{t}}+\lambda_{2} e^{y_{t}}\right) \\
V_{a} R_{\alpha}=F_{-R_{t}}^{-1}(\alpha)
\end{gathered}
$$

where $x$ and $y$ denote the simulated returns on crude oil and natural gas at a given point, and $\lambda_{1}$ and $\lambda_{2}$ are the portfolio weights of these assets. In Eq. (15), the $\operatorname{VaR}$ is simply defined as the $100 \alpha$-th percentile of the portfolio loss distribution.

A backtest is used to assess the accuracy of the $90 \%, 95 \%, 99 \%$, and 99.5\% $\operatorname{VaR}$ estimates. In the first step, we estimate at time $t_{0}$ the whole model (GARCH+GPD+Copula) using data only up to this time. Next, by simulating innovations from the best copula models, we obtain an estimate 
of the portfolio distribution and compute the $V a R$ using the estimated parameters of the GARCH model and the conditional mean term. This procedure is repeated until the last observation, and we compare the estimated $V a R$ with the actual next-day change in the portfolio's value. The whole process is repeated only once in every 50 observations owing to the computational cost of this procedure. However, at the arrival of each new observation, the $V a R$ estimates are modified because of changes in the GARCH volatility parameters and the conditional mean term. If the selected models are well suited for calculating $V a R$, the numbers of exceedances from these models should be close to the expected ones. Recall that the expected number of exceedances at the $(1-\alpha)$ confidence level over a backtesting period of $N$ days is equal to $\alpha . N$.

In practice, we begin with estimating the model using a window of 1850 observations. Then, we simulate 3000 values of the standardized residuals, estimate the $V a R$ and count the number of the losses that exceed these estimated $V a R$ values. At observations $t=1900,1950, \ldots, 3700$, we re-estimate the model and repeat the whole testing procedure.

For comparison purposes, we also estimate the $V a R$ for the oil and gas portfolio using two other approaches: the variance-covariance and the historical simulation methods. The first approach estimates the $V a R$ assuming that the portfolio returns follow a normal distribution. Let $\mu$ and $\sigma$ be the mean and the standard deviation of the portfolio returns, respectively, and $z_{\alpha}$ be the $(1-\alpha)$ quantile of the standard normal distribution for our chosen 
confidence level, the $V a R$ is computed as

$$
V a R=\mu-z_{\alpha} \cdot \sigma
$$

Despite its appealing simplicity, the variance-covariance method performs poorly in the presence of extreme events due to the normality assumption. Moreover, it may neglect the potential of nonlinear behavior of portfolio returns. The historical simulation method is a nonparametric and does not require any distributional assumptions. It estimates the $\mathrm{VaR}$ by means of ordered Loss-Profit observations. Concretely, assume that we have $N$ sorted simulated Loss-Profit observations, then the $V a R$ at the desired confidence level $(1-\alpha)$ corresponds to the $\alpha . N$-th order statistic of the sample. Like the variance-covariance method, historical simulations can be easily implemented, but the $V a R$ estimate depends greatly on the particular historical moving window. For example, if this method is applied just after an extreme event, let's say a specific crisis, this event will naturally be omitted from the window and the estimated $V a R$ may be very different.

For the variance-covariance and historical simulation methods, the model parameters are updated for every observation. The results for the backtesting are reported in Table 3. They show that extreme value copula-GARCH models outperform the alternative models, and provide more accurate $\mathrm{VaR}$ estimates for all the confidence levels considered.

We also use the Kupiec (1995) proportion of failures (POF) test and the 
Table 3: $V a R$ backtesting results

\begin{tabular}{|l|l|l|l|l|}
\hline \multicolumn{5}{|l|}{$\alpha$ [Expected number of exceedances] } \\
\hline Panel A & $0.1[185]$ & $0.05[92.5]$ & $0.01[18.5]$ & $0.005[9.25]$ \\
\hline & 195 & 95 & 15 & 3 \\
\hline Historical Simulations & 122 & 58 & 20 & 12 \\
\hline Variance-Covariance & 181 & 92 & 17 & 7 \\
\hline EVC-GARCH & Kupiec test & DQ test \\
\hline Panel B & 0.152 & 0.131 \\
\hline \multicolumn{7}{|l|}{} \\
\hline EVC-GARCH
\end{tabular}

Notes: This table reports the $V a R$ backtesting results obtained from the EVC-GARCH, the historical simulations and the variance-covariance method (Panel A). A model that is considered to be the best suited for calculating $V a R$ refers to the one with the number of exceedances closest to the expected one in bracket. It also presents the p-values for the Kupiec (1995) test and the DQ test of Engle and Manganelli (2004) using 5 lags and the current $V a R$ as explanatory variables.

dynamic quantile (DQ) test of Engle and Manganelli (2004) to check the robustness of the copula-GARCH model's results. The POF test examines the proportion of exceptions (i.e., the number of times the $V a R$ estimates is exceeded over a sample of $T$ observations) is consistent with the selected confidence level. Under the null hypothesis that the model is correctly specified, the empirical proportion of failures must be equal to the theoretical one (e.g., the theoretical failure rate is equal to $1 \%$ at the $99 \%$ confidence level). The POF test is conducted on the basis of a likelihood ratio statistic which follows the Chi-square distribution with one degree of freedomw. For its part, the DQ test focuses not only on the unconditional coverage (i.e., the frequency of exceptions), but also on the unconditional coverage by examining whether the exceptions occur independently of the others. According 
to the DQ test, a bad model for $V a R$ computations would be the one that produces a sequence of correlated exceptions.

The $p$-values associated with the POF and DQ tests with the $99 \%$ VaR confidence level are presented in Table 3 . They commonly show that the null

hypothesis of unconditional coverage (POF) and the joint null hypothesis of unconditional coverage and serial correlation of exceptions (QD) are rejected at the $1 \%$ level. This finding therefore confirms the relevance of our extreme value copula-GARCH model.

\section{Conclusions}

In contrast to previous literature, this paper investigates the extreme comovement and dependence between the crude oil and natural gas markets, using an extreme value copula-GARCH approach. We first employ a standard $\operatorname{GARCH}(1,1)$ to filter the considered return series and construct their marginal distributions. Various copula models are then fitted to the upper and lower tails of the GARCH-based standardized residuals. We finally show the implications of the empirical findings for risk management issues related to an oil and gas portfolio within a $V a R$ framework.

Our results show that the oil and natural gas markets generally comove closely together as the dependence parameters of all copulas models are highly significant. This result indicates that the crude oil and natural gas are generally complementary or substitutable through the relationship with the residual fuel oil. Improvement in the technology-based efficiency in one 
of these fuels should have implications for the other fuel. The facilities that are able to switch between natural gas and residual fuel oil should also influence their dependency. Their dependence does not also make them good substitutes in diversified portfolios, but their comovement makes them candidates for investment strategies like pair trade if they converge to some parity. These strateges entail long the contracts that are the underperformers, and short the contracts that are the outperformers.

At the extreme levels, we find asymmetric tail dependence between two markets. The results suggest that the daily oil and natural gas returns are only dependent in bullish market periods, but not so in bearish markets. This finding implies that stronger economic growth and concurrent energy demand strengthen the long-run relationship between them and make them responsive to common shocks such as changes in business cycles or geopolitical risk. The bullish relationship should encourage investment in fuel-switching facilities that involve both fuels and energy trades such as pairs trade. On the other hand, in bearish periods like the one we are in now where natural gas prices are at a record low as a result of low economic growth and improvement in extraction techniques, the relationship between those two fuels is weak. Recessions seem to weaken this relationship. If recession periods become more frequent and longer, we should accept the likelihood that the two prices will depart from each other more as a result of investments in single fuel facilities for natural gas usage. Households and businesses in the electricity power sector and industrial sectors will feel less uncertain and more secure 
about natural gas as a reliable energy source. On top of that, they will seek to enhance their cost effectiveness by switching to this relatively cheap and reliable fuel.

Since the daily oil and natural gas returns are only dependent in bullish market periods, but not so in bearish markets, it will be interesting to examine this bullish relationship within a 3-regime Markov switching framework where the third regime is the crash regime. In this case, one should be able to investigate the dependence in the crash regime and discern how this relationship changes. Another typical question would be whether holding the natural gas prices under long-term contracts disturbs the relationship between those highly dependent energy sources or reduces the possibility of holding long term contracts during bullish periods.

From an energy finance point of view, as the oil and natural gas prices divert apart in bearish periods, they may become over time more suitable to fit in diversified portfolios during bearish periods. The fitness may increase as time goes on because of building more single fuel facilities for natural gas. On the other hand, since natural gas, as is the case for oil, is increasingly being used as a surface fuel and more vehicles will be fueled by natural gas, the dependence between those two fuels will increase and their prices would move more closely especially during bullish periods. The long-term price contracts may in this case lose traction and the two fuel may come closer to each other in the future.

Our portfolio simulations provide more accurate $V a R$ forecasts for an 
equally-weighted oil and gas portfolio than the variance-covariance and historical simulation methods. This result thus implies that the proposed extreme value copula-GARCH model can improve the accuracy of the market risk forecasts for such an oil and gas portfolio.

\section{References}

[1] Abad, P., Chuliá, H., Gómez-Puig, M., 2010. EMU and European government bond market integration. Journal of Banking and Finance 34, $2851-2860$.

[2] Accioly, R.M., Aiube, F.A., 2008. Analysis of crude oil and gasoline prices through copulas. Working Paper, Pontifical Catholic University of Rio de Janeiro.

[3] Alexander, C., 2004. Correlation in crude oil and natural gas markets. In Managing Energy Price Risk: The New Challenges and Solutions, 3rd Edition, Chapter 17, 573-604. Risk Books, London.

[4] Aloui, R., Ben Aïssa, M.S., Nguyen, D.K., 2011. Global financial crisis, extreme interdependences, and contagion effects: The role of economic structure? Journal of Banking and Finance, 35, 130-141.

[5] Aloui, R., Ben Aïssa, M.S., Nguyen, D.K., 2013. Conditional dependence structure between oil prices and exchange rates: A copula-GARCH approach. Journal of International Money and Finance 32, 719-738. 
[6] Aloui, C., Jammazi, R., 2009. The effects of crude oil shocks on stock market shifts behaviour: A regime switching approach. Energy Economics 31, 789-799.

[7] Arouri, M., Lahiani, A., Lévy, A., Nguyen, D.K., 2011. Forecasting the conditional volatility of oil spot and futures prices with structural breaks and long memory models. Energy Economics 34, 283-293.

[8] Asche, F., Osmundsen, P., Sandsmark, M., 2006. The UK market for natural gas, oil and electricity: are the prices decoupled? Energy Journal $27,27-40$.

[9] Bae, K.-H., Karolyi, G.A., Stulz, R.M., 2003. A new approach to measuring financial contagion. Review of Financial Studies 16, 717-763.

[10] Basel Committee on Banking Supervision, 1996. Supervisory framework for the use of "backtesting" in conjunction with the internal model-based approach to market risk capital requirements. Bank for International Settlements, Basel, Switzerland.

[11] Baur, D., Schulze, N., 2005. Coexceedances in financial markets - a quantile regression analysis of contagion. Emerging Markets Review 6, $21-43$.

[12] Benth, F.E., Kettler, P.C., 2011. Dynamic copula models for the spark spread. Quantitative Finance 11, 407-421. 
[13] Bollerslev, T., 1986. Generalized autoregressive conditional heteroskedasticity. Journal of Econometrics 31, 307-327.

[14] Brown, S., Yucel, M., 2010. What drives natural gas price? Energy Journal 29, 43-58.

[15] Chan-Lau, J.A., Mathieson, D.J., Yao, J.Y., 2004. Extreme contagion in equity markets. IMF Staff Papers 51, 386-408.

[16] Choe, G.H., Jang, H.J., 2011. Efficient algorithms for basket default swap pricing with multivariate Archimedean copulas. Insurance: Mathematics and Economics 48, 205-213.

[17] Christiansen, C., Ranaldo, A., 2009. Extreme coexceedances in new EU member states' stock markets. Journal of Banking and Finance 33, 10481057.

[18] De Melo Mendes, B.V., 2005. Asymmetric extreme interdependence in emerging equity markets. Applied Stochastic Models in Business and Industry 21, 483-498.

[19] Fermanian, J.-D., 2005. Goodness-of-fit tests for copulas, Journal of Multivariate Analysis 95, 119-152.

[20] Frank, M.J., 1979. On the simultaneous associativity of $F(x, y)$ and $x+y-F(x, y)$. Aequationes Mathematicae 19, 194-226. 
[21] Forbes, K., Rigobon, R., 2002. No contagion, only interdependence: Measuring stock market comovements. Journal of Finance 57, 22232261.

[22] Galambos, J., 1975. Order statistics of samples from multivariate distributions. Journal of American Statistical Association 70, 674-680.

[23] Genest, C., Kojadinovic, I., Nešlehová, J., Yan, J., 2011. A goodness-offit test for bivariate extreme-value copulas. Bernoulli 17, 253-275.

[24] Genest, C., Quessy, J.F., Rémillard, B., 2006. Goodness-of-fit procedures for copula models based on the integral probability transformation. Scandinavian Journal of Statistics 33, 337-366.

[25] Gilmore, C.G., Lucey, B., McManus, G.M., 2008. The dynamics of central European equity market comovements. Quarterly Review of Economics and Finance 48, 605-622.

[26] Grégoire, V., Genest, C., Gendron, M., 2008. Using copulas to model price dependence in energy markets. Energy Risk 5, 58-64.

[27] Gumbel, E.J., 1960. Multivariate extremal distributions. Bulletin de l'Institut International de Statistique 37, 471-475.

[28] Hartley, P.R., Medlock, K.B., Rosthal, J.E., 2008. The relationship of natural gas to oil prices. Energy Journal 29, 47-66. 
[29] Husler, J., Reiss, R.D., 1987. Extreme value theory. Lecture Notes in Statistics, Springer-Verlag, Berlin.

[30] Joe, H., 1997. Multivariate models and dependence concepts. Chapman \& Hall Ltd.

[31] Joe, H., Xu, J., 1996. The estimation method of inference functions for margins for multivariate models. Technical Report 166, Department of Statistics, University of British Columbia.

[32] Jondeau, E., Rockinger, M., 2006. The copula-GARCH model of conditional dependencies: An international stock market application. Journal of International Money and Finance 25, 827-853.

[33] Kojadinovic, I., Yan, J., 2010. Modeling multivariate distributions with continuous margins using the copula $\mathrm{R}$ package. Journal of Statistical Software 34, 1-20.

[34] Longin, F., Solnik, B., 2001. Extreme correlation of international equity markets. Journal of Finance 56, 649-676.

[35] Nelsen, R. B., 1999. An introduction to copulas. Springer, NewYork.

[36] Ning, C., 2010. Dependence structure between the equity market and the foreign exchange market: a copula approach. Journal of International Money and Finance 29, 743-759. 
[37] Palaro, H.P., Hotta, L.K., 2006. Using conditional copula to estimate Value at Risk. Journal of Data Science 4, 93-115.

[38] Regnier, E., 2007. Oil and energy price volatility. Energy Economics 29, $405-427$.

[39] Sadorsky, P., 2006. Modeling and forecasting petroleum futures volatility. Energy Econ. 28, 467-488.

[40] Serletis, A., Herbert, J., 1999. The message in Noth American energy price. Energy Economics 21, 471-483.

[41] Villar, J.A., Joutz, F.R., 2006. The relationship between crude oil and natural gas. Energy Information Administration, Office of Oil and Natural Gas, Washington, D.C.

[42] Yucel, M.K., Guo, S., 1994. Fuel taxes and cointegration of energy prices. Contemporary Economic Policy 12, 33-41. 